\title{
Implementation of Web based Technique into the Intelligent Manufacturing System
}

\author{
Ali Mostafaeipour \\ Industrial Engineering Department \\ Yazd University \\ Yazd, Iran
}

\author{
Nirjhar Roy \\ Mechanical Engineering Department \\ MNNIT \\ Allahabad, UP, India
}

\begin{abstract}
Intelligent Manufacturing System (IMS) shall be considered as a system integrated with different intelligent subsystems, which completes the distributed solution procedure on the basis of exchanging large quantities of materials, energy and information. Any intelligent manufacturing process selfregulates and self-controls itself in manufacturing the products within the design specifications. It incorporates introduction of human-like decision-making capabilities into the manufacturing system that brings the intelligence. The system however requires complete information of the requirements and processing of production system to generate appropriate decisions. This paper provides a comprehensive review of research on web-enabled e-Manufacturing technology which bridges certain aspects of manufacturing system like Customer Relationship Management (CRM), Enterprise Resource Planning (ERP), and Supply Chain Management (SCM). Web-based systems have been implemented to provide remote service and manufacturing for rapid prototyping, enhance the availability of facilities and improve the capability of rapid product development for various enterprises. Web-based technique is utilized to derive the availability of information anytime, anywhere and by the persons who are authorized to deal with it. The eManufacturing production system can substantially reduce product cost and delivery cycle for manufacturing systems.
\end{abstract}

\section{Keywords}

Intelligent Manufacturing System (IMS); Web Based; eManufacturing; Internet; multi-agent.

\section{INTRODUCTION}

Information technology (IT) and intensification of trend in Economic Globalization, manufacturing system has to face the increasingly fierce market competition. "Today's highly competitive; fast pace business environment makes it an absolute requirement on behalf of the managers to continuously make the best decisions in the shortest possible time. The notion of 'learning from mistakes' has left its place to 'one strike and you're out' reality. That is, there is no room for error in making managerial decisions in this global environment marked by mergers, acquisitions, and everincreasing economic instability. Success (or mere survival) depends on quickly aligning the organizational resources towards meeting (and exceeding) the actual (and perceived) needs and wants of the customer [1]."

It is very important to do a right decision in manufacturing systems. The decision-making life cycle for manufacturing systems managers is illustrated in Figure 1. Clearly, decision makers are constantly exposed to threats, strengths, weaknesses, and opportunities. (as is the case in many business environments nowadays). In order to solve the problems and/or take advantage of the opportunities, managers have to make best decisions, which may result in changing the manufacturing system. Best possible decisions must be implemented by managements for manufacturing system [1].

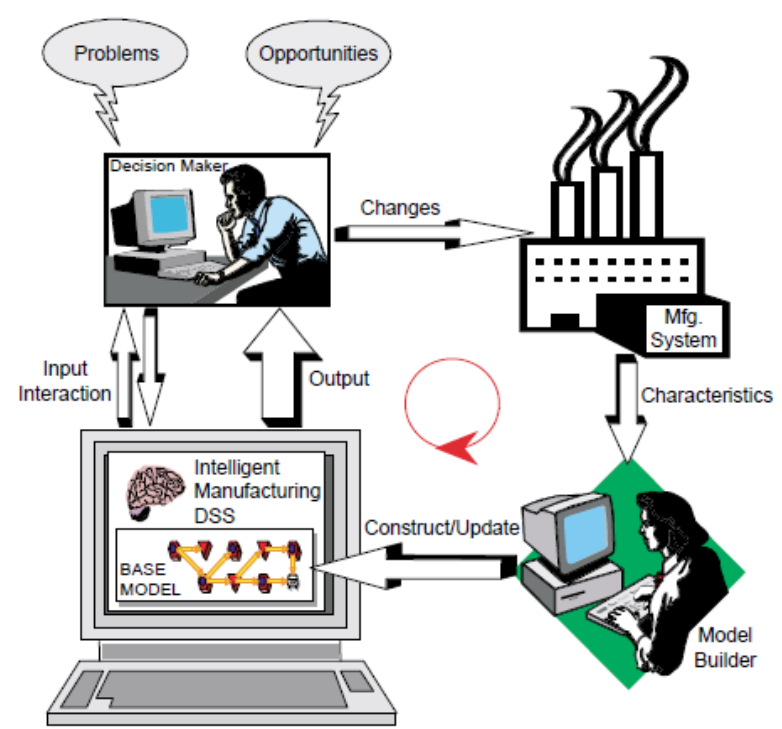

Fig 1: Manufacturing systems decision making life cycle [1].

In the past, mass production system has typically been utilized by manufacturing companies as a minimum cost method to produce large volume of products/parts for internal inventory buffer or Just-In-Case deliveries. This method allows expensive setup cost to be distributed to entire batch under production. "In the last decades world has moved towards a global economy, with markets demanding for products with high quality at lower costs, highly customized and with short life cycles, imposing new requirements on manufacturing enterprises, namely in terms of quality, response, agility and flexibility, that are crucial for an enterprise staying in the business [2]."Two other new important production systems have also evolved in the recent past. They are: Lean Production and Agile Manufacturing Systems. Lean Production aims at reduction of production cost through trimming down unnecessary wastes (such as setup cost, workin-process, etc.) and perfecting quality at first-instance (i.e., zero defect) of products.

Globally, lean production has been expanded and lean thinking has been applied to all aspects of the supply chain. There are different application of 'lean thinking' to business 
processes such as project management construction, design, and so on $[3,4]$.

Agile Manufacturing, on the other hand, does focus on the restructure of manufacturing organization and operation procedures so that it can react to rapidly changing markets, and shorten new product's Time-To-Market cycle. Gunasekaran [5,6,7] defines agile manufacturing as "the capability to survive and prosper in a competitive environment of continuous and unexpected change by reacting quickly and effectively to changing markets, driven by customer-designed products and services." Goldman et al. $[5,8]$ believe agile manufacturing allows companies to be capable of operating profitably in a competitive environment of continually and unpredictably changing customer opportunities [5]. Agile manufacturing can also be defined as "capability of surviving and prospering in a competitive environment of continuous and unpredictable change by reacting quickly and effectively to changing markets, driven by 'customer-defined' products and services. $[9,10]$ "

In general, Lean Production addresses more on product cost issues, while Agile Manufacturing emphasizes more on product delivery cycle issues. Lean and agile manufacturing are considered as a starting point of implementing intelligent manufacturing as a myriad of components are needed to be produced in a short span and manual or automated methods cannot cope up with the system.

Companies must consider strategic initiatives such as agile manufacturing systems to compete globally and respond to dynamic customer demand [5]. One of the goals of agile manufacturing is to produce customized products in a short time at lowest possible cost. For this purpose in a manufacturing system, products are differentiated either by a machining-driven or an assembly-driven differentiation strategy. The structure of the manufacturing system that implements the assembly-driven product differentiation strategy in agile manufacturing is illustrated in Figure 2. The manufacturing process in the system consists of two steps: machining and assembly [11].

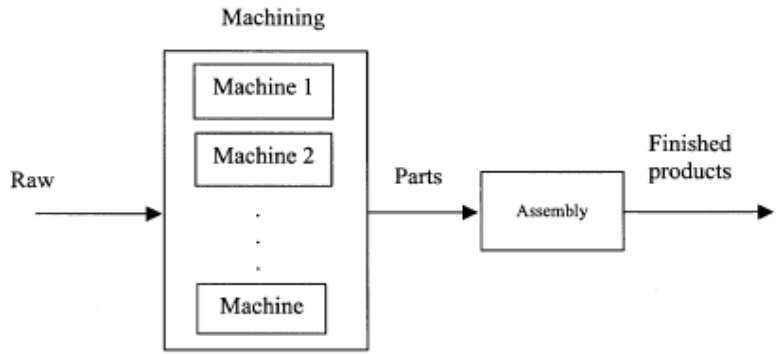

Fig 2: The general structure of the manufacturing system [11].

Powerful computers, advances in communication and other technological and scientific areas are integrated and utilized in the area of Intelligent Manufacturing Systems. It has become quite clear that the requirements in the modeling and control of systems cannot be met only with the existing conventional theories. It is necessary to investigate and use new methods that will exploit human experience, will have learning capabilities, and will be supplied with fault- detection and identification characteristics including imprecision and uncertainty. An Intelligent Manufacturing System should therefore utilize effectively all the company resources, especially the insights and experience of front-line operators and experts in order to achieve continuous improvements in productivity. One of the major objectives of the Intelligent Manufacturing System initiative [12] is to contribute to the development of new production systems that can fulfill technical, economic and environmental requirements for optimality and sustainability while maintaining their competitiveness. This necessitates enhancement of the flexibility, reusability, availability, dependability of the production system [13]. For this purpose the authors of this paper have proposed implementation of e-Manufacturing as a way to implement Intelligent Manufacturing System.

The ability to connect Intranet/Intranet at factory floor, and be accessible globally through embedded Web server residing in PLC controllers or mobile devices has making the implementation of Web Enabled factory possible. The recent development and deployment of wireless data communication networks (such as CDPD, GPRS, and Bluetooth), and satellite position technology (such as GPS) have extended the Web Enabled factory even further into wireless and mobile communication domain.

The primary objective of e-Manufacturing [14] is to fulfill the online orders from consumers or business partners (i.e. eBusiness) through the real-time execution of:

- Product Design,

- Production Planning and Scheduling,

- Manufacturing Process and Control,

- Distribution and Delivery cycle via Internet and Internet connectivity.

Figure 3 shows these four components of execution cycle. In supporting e-Manufacturing, real-time collaborations with other e-Business systems, such as SCM (Supply Chain Management), ERP (Enterprise Resource Planning), and CRM (Customer Relationship Management) are also needed, if these systems have been implemented by manufacturing companies. This paper discusses only the Manufacturing Process and Control portion of the e-Manufacturing cycle which is concerning with the management and control of actual operations of manufacturing facilities.

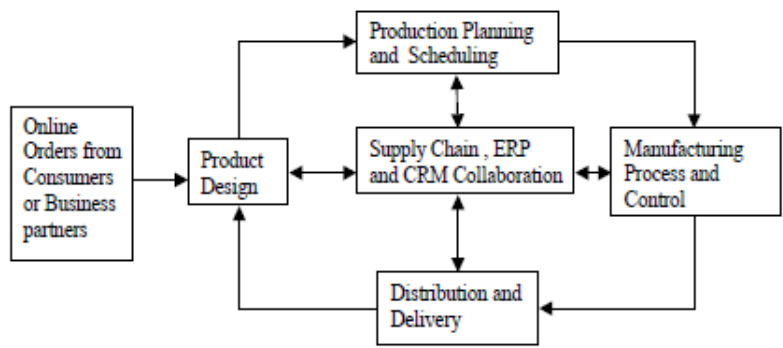

Fig 3: Real-Time Execution of e-Manufacturing Cycle [14].

\section{HIERARCHY OF INTERNET ENABLED CONTROL MANUFACTURING}

The hierarchy of Internet Enabled manufacturing control at factory floor can be divided into three layers [15] as shown in Figure 4. The lower layer of manufacturing control is at workstation level where one principal machine with one controller is used. 


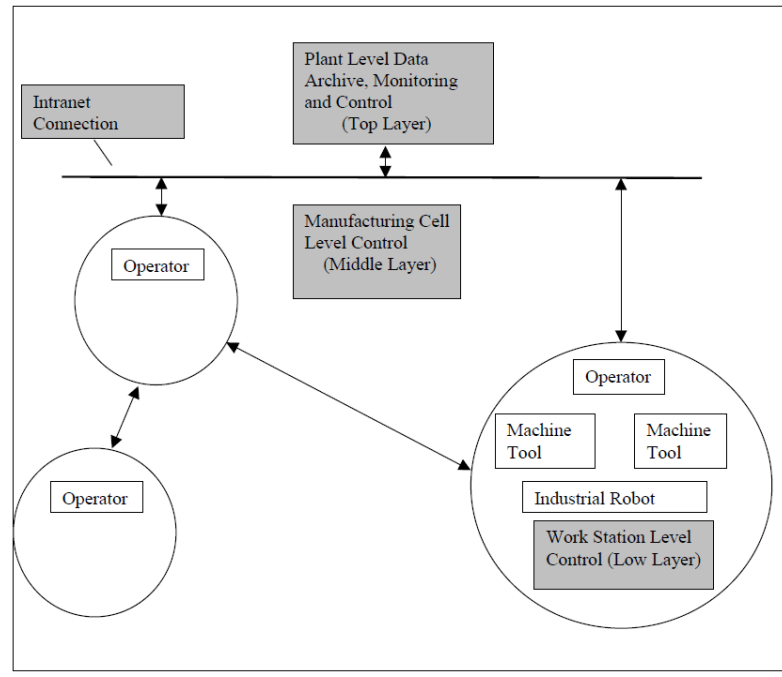

Fig 4: Hierarchy of Internet enabled Manufacturing Control at Factory Floor [15].

Typical controller in this level is PLC (Programmable Logic Controller) that can be used to control CNC machines, handling systems (such as conveyor, AGVs, etc). The middle layer of manufacturing control is at machine cell or machine cluster where a set of machines and controllers are used to work together for planned tasks. Typical controllers in this level are DNC (Distributed Numerical Controller), and Remote Terminal Unit (RTU) Controller. The top layer of manufacturing control is at plant floor where control functions, such as data acquisition, data monitoring, process control, and alarm trigging, are handled.

The goal of Internet Enabled manufacturing control is to move the object-based data directly from field controllers or mobile devices (i.e., at low layer) to plant level (i.e., at top layer), and eventually to enterprise level so that data and information can be accessed by other system components, such as product design, production planning and scheduling, distribution and delivery. To achieve this objective, an Intranet connection at factory floor and Internet connection at business office are required. Security setup and configuration for firewall and Proxy Servers are also necessary in emanufacturing environment. As wireless communication become cheaper and affordable, real-time wireless monitoring and control of plant operations will also be an important option.

\section{INTELIGENT MANUFACTURING SYSTEM BASED ON IMPROVED MULTI-AGENT}

There are different definitions for the term "Agent". Wooldridge and Jennings [16] define agent as: "An agent is a computer system that is situated in some environment, and that is capable of autonomous action in this environment in order to meet its design objectives". "A multi- agent system includes number of agents that work together to solve problems that are beyond the individual capabilities or knowledge of each entity. These agents interact with one another, typically by exchanging messages through the computer network infrastructure. Cooperation and coordination between agents is the most important feature of multi-agent systems [17]. Agents communicate for the purpose of cooperation and negotiation, learning to improve performance over time [18]. The collaborations between the agents in a multi-agent system tend to take one agent's output as another agent's input without directly utilizing the agent's built-in knowledge model [19, 20, and 21]."'

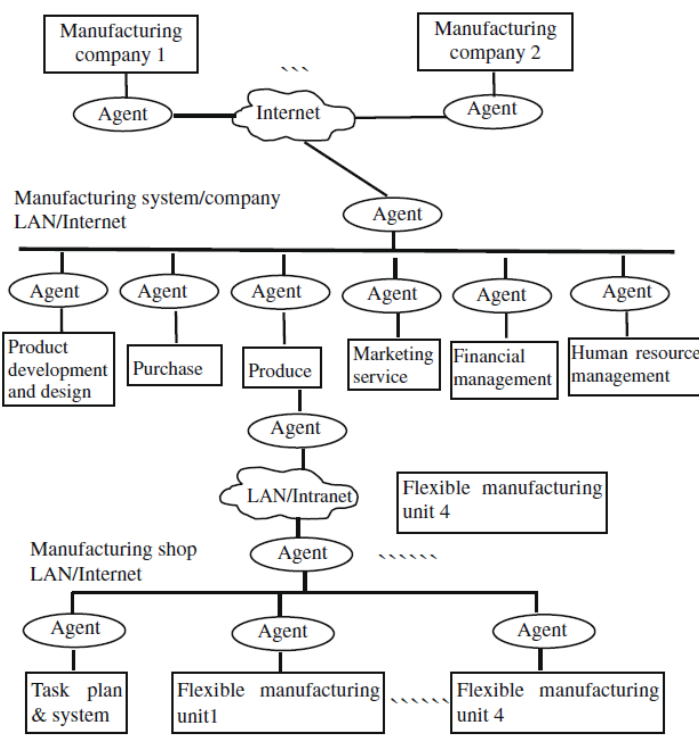

Fig 5: Network model block graph [27].

The main types of Intelligent Manufacturing Systems (IMS) are: Intelligent Manufacturing System that takes the improvement of manufacturing system intelligence as the object and takes intelligent robot and Agent as the tool; Intelligent Manufacturing System that integrates the modeling, processing, measurement and operation of corporations through Internet; biological Intelligent Manufacturing System that adopts solution procedure for biological problems [22, 23, and 27]. The distributed network Agent-based IMS model is illustrated in Figure 5. Multi-agent system is composed of a group of Agents that distributed at logical or physical positions [24-27]. Clearly, each manufacturing unit is endowed with autonomy by Agent to become the entity with perfect functions and autonomy independence; on the other hand, the system is endowed with self-organization capacity through the coordination and cooperation among Agents [27].

\section{JAVA ENABLED AND WEB TECHNOLOGIES FOR E- MANUFACTURING}

Recently, many established global manufacturing networks have been taking advantage of information technologies and fast growing networks [28]. "The rapidly changing needs and opportunities of today's global market require unprecedented levels of interoperability to integrate diverse information systems to share knowledge and collaborate among organizations. The combination of Web services and software agents provides a promising computing paradigm for efficient service selection and integration of inter-organizational business processes [29]."

Web technologies which are built on the top of Internet/Intranet connectivity go beyond simple www (World Wide Web) access. It is a group of new technologies that uses Internet Enabled languages as foundation to create powerful server-side Web applications, such as dynamic content searching and manipulations, internal and external 
database access, etc. Traditional approaches for Web access, such as Common Gateway Interface (CGI) [30], have been gradually replaced with Java based system, such as JSP (JavaServer Page) [31], Java Servlets [32], RMI (Remote Method Innovation) [33], JMS (Java Message Services) [34], etc.

"As one of the most popular Internet tools, the Web aims to provide a light-weight and an operating system independent platform for users to search, browse, retrieve and manipulate information disseminated and shared remotely. Based on the Web, design models can be dynamically shared and updated in an Internet environment and conveniently accessed and manipulated by remotely located people from the design team, management, marketing, maintenance and customers for efficient design collaboration, design process monitoring, product pre review and evaluation. Realizing the merits of the Web technology, researchers and developers have been actively exploring and developing Web-based design and manufacturing systems" [33].

Java is an object-oriented and hardware independent computer programming language. Java 2 Enterprise Edition (J2EE) [34], a latest version of Java language, is aiming for the development of enterprise, multi-tier Web applications. Such applications are typically including a client tier to provide necessary user interface, one or more middle-tier to provide applications for business logic and client services, and a backend enterprise system for data management. The J2EE platform provides a comprehensive framework and architecture for designing, executing, and integrating the enterprise information from e-Business to e-Manufacturing (This has been elaborated in detail by Slansky Dick [34]). Various elements of the J2EE platform, such as Enterprise JavaBeans (EJB) [34], and JSP/Servlets, are enabling manufacturing companies to deploy new applications that are specific to business requirements, and plug it into existing system quickly.

One such implementation is by Sun Microsystems's Java Embedded Server (JES) [44], a small-footprint Web application server, provides powerful and versatile capabilities to support embedded application development at factory floor in e-Manufacturing environment. Embedded applications run on microcontroller and are residing within electronic devices. JES is a service-driven network application, allows device's services to be created, registered, and later to be discovered and used at run-time. In the Intelligent e-Manufacturing Control System, described in the following section, J2EE is used to develop the eManufacturing Control Server and JES is used to develop the e-Manufacturing Plant Gateway. By taking advantages of the effective utilizations of the Web and Java technologies, this system is could operate properly.

\section{INTELIGENT E-MANUFACTURING CONTROL SYSTEM}

E-manufacturing perceptions started originally from the idea of the factory of the future, E- business/commerce application in manufacturing and the extension of computer networking technology. Basically, E-manufacturing integrates customers, e-commerce systems, and suppliers with manufacturing process to provide an Internet-based strategic framework for the factory [35-40].

Intelligence in manufacturing is perceived in different ways ranging from intelligent control and information communication techniques through human intelligence in the operating/engineering loop to agents' self-organization [41, 42]. "The area of intelligent systems is challenging - to an extent occasionally verging on controversy - both the research community and the industrial sector to cope with the traditional and centralized automation approaches to meet the high degree of complexity and practical requirements for robustness, generality and reconfigurability in manufacturing control as well as in production management, planning and scheduling" [42].

Intelligent e-Manufacturing Control System that combines Business Rule Engine technology and Autonomous Agent technology forms an integrated Web application server. It can be used to manage and control many manufacturing functions, such as shop floor control, inventory control, logistic and distribution. "Manufacturing has faced significant changes during the last years, namely the move from a local economy towards a global and competitive economy, with markets demanding for highly customized products of high quality at lower costs, and with short life cycles. In this environment, manufacturing enterprises, to remain competitive, must respond closely to customer demands by improving their flexibility and agility, while maintaining their productivity and quality. Dynamic response to emergence is becoming a key issue in manufacturing field because traditional manufacturing control systems are built upon rigid control architectures, which cannot respond efficiently and effectively to dynamic change [2]."

\subsection{Key Components of Intelligent E- Manufacturing Control System}

There are two key components in the intelligent eManufacturing Control System: e-Manufacturing Control Server and e-Manufacturing Plant Gateway, as shown in Figure 6. The reason for separate server at plant level is that most of devices and controllers at factory floor today are not Internet Enabled. It will take some time for Internet technology to be integrated into those devices and controllers. The Plant Gateway which contains an embedded Web Server is a middleware that can fill this gap. These two components are described further below:

\subsubsection{E-Manufacturing Control Server}

The Control Server contains business related applications which are implemented in J2EE Enterprise JavaBeans (EJB). These applications include data compression, data archive, data monitoring and control, information collaborations with SCM, ERP, CRM, etc. Data and business rules are stored in a Data Management System (DBMS) and can be accessed at run-time. JSP/Servlet is used for direct synchronous based applications, while Java Messaging Services (JMS) is used for asynchronous based applications when direct connection is not available. The e-Manufacturing Control Server is running under a J2EE Based Web Application Server, which is bundled with an Apache Web Server.

\subsubsection{E-Manufacturing Plant Gateway}

The Plant Gateway is running under a Real-Time Operation System (RTOS) [43], and including an embedded Java Virtual Machine (JVM) [44]. Java Embedded Server (JES) is used for discovering and executing of various services registered by autonomous agents. The Plant Gateway can also include a wireless communication transceiver to link to wide-area cellular network or local RF network. An optional GPS module can be included in the Plant Gateway for tracking product movement. 


\subsection{Core Technologies in Intelligent $\mathrm{E}$ - Manufacturing Control System}

There are two core technologies that the intelligent eManufacturing Control Systems are based on:

\subsubsection{Business Rules and Generic Rule Engine}

The core technology of the Control Server is JavaBeans Based Business Rules and Generic Rule Engine. Business rules are logic units used by manufacturing companies to conduct its business and manufacturing functions.

\subsubsection{Autonomous Intelligent Agent Controller and Services}

The core technology of the Plant Gateway is Autonomous Intelligent Agents Controller and related agent services. The implementation of Autonomous Intelligent Agent Controller is based on a formal agent framework which is useful in real life applications [44]. This technology defines a three-tiered hierarchy comprising of objects, agents, and autonomous agents where agents are viewed as objects with goals.

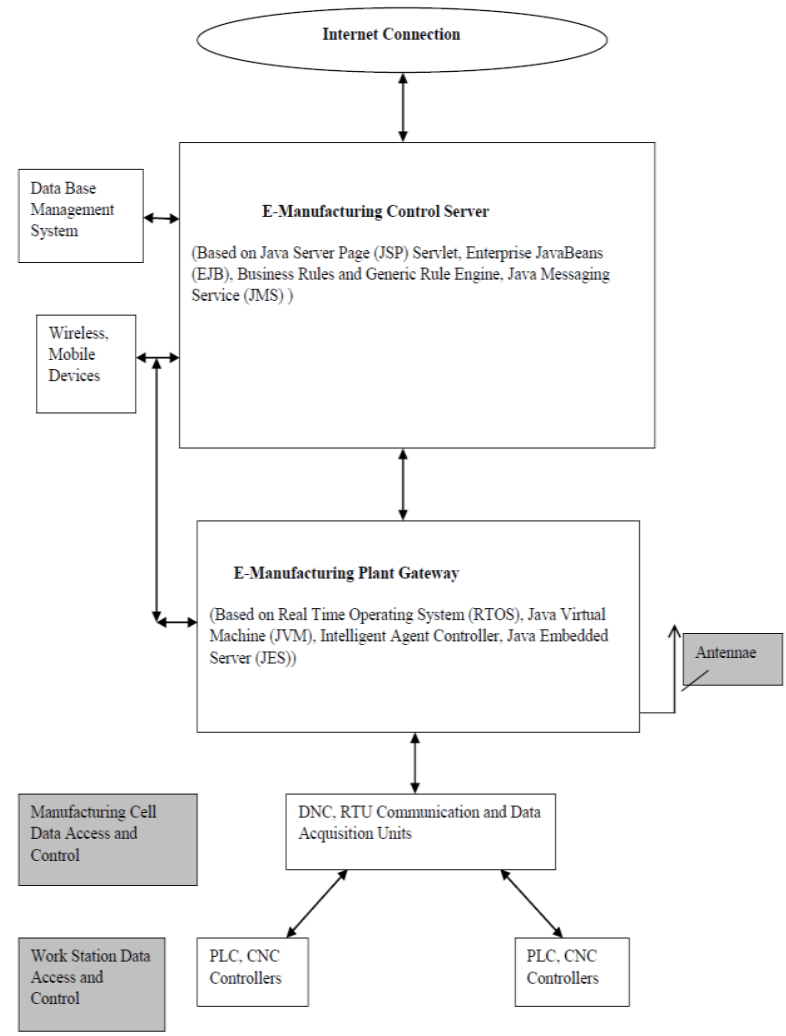

Fig 6: Key Components of Intelligent e-Manufacturing Control System [44].

\section{CONCLUSION}

In this paper, an effective method for Implementation of Web Based Technique into the Intelligent Manufacturing System has been presented. It also discusses an Internet Enabled Manufacturing Control System of e-Manufacturing cycle. The potential benefits of the Internet Enabled Manufacturing Control System can be summarized as the follows:-

- Speeding product delivery cycle through internet/intranet connection for real-time data exchange between plant level and enterprise level.

- Reducing product cost through reconfigurable product design and mass customization manufacturing.
- Preventing unexpected production breakdown through realtime monitoring and control of factory operations anytime, anywhere.

- Maximizing material synchronization process through material requirement and delivery information exchange with Supply Chain Management system.

- Improving resource utilization by supplying realtime plant information to Enterprise Resource Planning system.

- Increasing customer satisfactory and royalty through information sharing with Customer Relationship Management system.

These benefits can be fully realized when the entire execution cycle of e-Manufacturing is implemented in Manufacturing System which would yield to lower expences.

\section{REFERENCES}

[1] Delen, D., Pratt, D. B., 2006. An integrated and intelligent DSS for manufacturing systems. Expert Systems with Applications. 30, 325-336.

[2] Leitao, P., 2009. Agent -based distributed manufacturing control: A State of the art Survey Engineering. Applications of Artificial Intelligence. 22, 979-991.

[3] Melton, P.M., 2003, Agile project management for API projects: get Agile - deliver faster, Proceedings of the ISPE European Conference, Brussels, Belgium.

[4] Melton, T., 2005. The benefits of lean manufacturing: What Lean Thinking has to Offer the Process Industries. Chemical Engineering Research and Design. 83(A6), 662-673

[5] Elkins, D. A., Huang, N., Alden, J. M., 2004. Agile manufacturing systems in the automotive industry. Int. J. Production Economics. 91, 201-214

[6] Gunasekaran, A., 1998. Agile manufacturing: Enablers and an implementation framework. International Journal of Production Research. 36 (5), 1223-1247.

[7] Gunasekaran, A., 1999a. Editorial: Design and implementation of agile manufacturing systems. International Journal of Production Economics. 62, 1-6.

[8] Goldman, S.L., Nagel, R.N., Preiss, K., 1995. Agile Competitors and Virtual Organizations-Strategies for Enriching the Customer. Van Nostrand Reinhold, New York.

[9] ] Cho, H., Jung, M., Kim, M., 1996. Enabling technologies of agile manufacturing and its related activities in Korea. Computers and Industrial Engineering. 30(3), 323-334.

[10] Gunasekaran, A., Tirtiroglu, E., Wolstencroft, V., 2002. An investigation into the application of agile manufacturing in an aerospace company. Technovation. $22,405-415$.

[11] He, D., Babayan, A., Kusiak, A., 2001. Scheduling manufacturing systems in an agile environment. Robotics and Computer Integrated Manufacturing. 17, 87-97.

[12] IMS, "IMS: Intelligent Manufacturing Systems, A Program for International Cooperation in Advanced Manufacturing", Final Report of the International Steering Committee adopted at ISC6, Hawaii.(Jan 1994), 24-26. 
[13] Sousa, P., Silva, N., Heikkila, T., Kollingbaum, M. and Valckenaers, P., 1999. "Aspects of Co-operation in Distributed Manufacturing Systems", in H. Van Brussel and P. Valckenaers (Eds.) Proceedings of the $2^{\text {nd }}$ Workshop on Intelligent Manufacturing Systems, Leuven. (September 22-24), 695 - 717.

[14] Rockwell Automation Inc., 2001"Making Sense of emanufacturing: A Roadmap for Manufacturers", RJI, August ,Solutionn: 1(3),78-95

[15] Yong-Mi Kim, Basili Victor, Manoel Mendonca, Carolyn Seaman and Richard Webby,2004,"Implementing an Internet-Enabled Software Experience Factory:Work in progress" ICCT,8(1), 101-109

[16] Wooldridge, M., Jennings, N. R.,1995. Intelligent agents: Theory and practice. The Knowledge Engineering Review, 10(2), 115-152.

[17] Peng, Y. et al., 1998. A multi-agent system for enterprise integration. In Proceedings of the third international conference on the practical applications of agents and multi-agent systems (PAAM-98) (pp. 1-14).

[18] Wooldridge, M., Jennings, N. R.,1999. Software engineering with agents: Pitfalls and pratfalls. IEEE Internet Computing, 3(5/6), 20-27.

[19] Chao, K. M., Smith, P., Hills, W., Florida-James, B., Norman, P.,1998. Knowledge sharing and reuse for engineering design integration. Expert System with Application, 14(3), 399-408.

[20] Jennings, N. R. et al., 1996. Using ARCHON to develop real-word DAI applications, Part I. IEEE Expert. 11(6), 64-70.

[21] Gao, Y., Shang, Z., Kokossis, A., 2009. Agent-based intelligent system development for decision support in chemical process industry. Expert Systems with Applications, 36,11099-11107.

[22] Qiao, B., Zhu, J.Y., 2001. Agent-based intelligent manufacturing systems: a state-of-the-art survey. J. Nanjing Univ. Aeronaut. Astronaut. 38, 3-13.

[23] Huang, C.Y., Cheng, K., Holt, A. 2007. An integrated manufacturing network management framework by using mobile agent. Int. J. Adv. Manuf. Technol. 32, 822-833.

[24] Lim, M.K., Zhang, Z., 2000. Integrated manufacturing systems control using a multi-agent system, in: Proceedings of 33rd International MATADOR Conference. pp. 9-14, ISBN:1-85233-323-5.

[25] Baek, J.W., Yeom, H.Y., 2006. A timed mobile agent planning approach for distributed information retrieval in dynamic network environments. Inf. Sci. 176, 33473378.

[26] Medani, O., Ratchev, S.M., 2006. A STEP AP224 agentbased early manufacturability assessment environment using XML. Int. J. Adv. Manuf. Technol. 27, 854-864.

[27] Guo, Q., Zhang, M., 2009. A novel approach for multiagent-based Intelligent Manufacturing System. Information Sciences. 179, 3079-3090.

[28] Shi, y., Gregory, M. J., Naylor, M.,1997. International manufacturing configurations map: a self assessment tool of international manufacturing capacities. Integrated manufacturing Systems. 8(5), 273-282.

[29] Shen, W., Hao, Q., Wang, S., Li, Y., Ghenniwa, H., 2007. An agent-based service-oriented integration architecture for collaborative intelligent manufacturing. Robotics and Computer-Integrated Manufacturing. 23, 315-325.

[30] Gundavaram, S., 1996. Common Gateway Interface, Overview. CollabNet,221-228.

[31] Hunter, J., 2006. The Problems with JSP. Internet Journal,12(1),106-132.

[32] Mehta, N., 2002, A Brief Introduction to RMI. CMU Journal. 20,65-75.

[33] Li, W.D., Ong, S.K., Nee, A.Y.C., 2005. A Web-based process planning optimization system for distributed design. Computer-Aided Design. 37, 921-930.

[34] Dick, S. "Java Technology Powers E-Manufacturing", Arch Advisory Group, White Paper of SUN Microsystems, Inc., September, 2001.

[35] Tiwari, M.K., Jha, S. K., Anand, R. B., 2010. Operation allocation and part type selection in E-manufacturing: Anauction based heuristic supported by agent technology. Robotics and Computer-Integrated Manufacturing. 26, 312-324.

[36] Koc, M., Ni, J., Lee, J., 2003. Introduction of emanufacturing NAMRC, E- manufacturing panel. McMaster University; May 2003.

[37] Jay, L., 2003. E-manufacturing- fundamental, tools, and transformation. Robotics and Computer Integrated Manufacturing.19,501-7.

[38] Lee, J., Ni, J., 2002. Infotronics agent for tether-free prognostics. In: Proceeding of the AAAI spring symposium on information refinement and revision for decision making: modeling for diagnostics, prognostics, and prediction. Stanford University, Palo Alto, CA. March 25-27.

[39] Rockwell automation e-manufacturing industry roadmap, www. rockwellautomation.com.

[40] Ni, J., Lee, J., Djurdjanovic, D., 2003. Watchdog information technology for proactive product maintenance and ecological productive use .In: Proceeding of the colloquium on E-ecological manufacturing, Technical University of Berlin, Germany, March 2003.

[41] Lhote, F., Chazelet, Ph., Dulmet, M.,1999. The extension of principles of cybernetics towards engineering and manufacturing. IFAC Annual Reviews in Control. 23(1), 139-148.

[42] Morel, G., Valckenaers, P., Faure, M. C., Pereira, C. E., Diedrich, C., 2007. Manufacturing plant control challenges and issues. Control Engineering Practice. 15,

[43] Mikell P. Groover, 2007 Automation, Production Systems, and Computer-Integrated Manufacturing, 3/E, Prentice Hall ,N.Y

[44] Roy, N., Mostafaeipour, A., 2005. Intelligent Manufacturing System through Web Based Technique. International Conference of Industrial Engineering, Theory Practice and Applications. Clearwater Beach, Florida, USA. 